\title{
Sustaining partnership working in practice learning: An exploration of the perspectives of practice teachers and students
}

\section{Ian Brodie ${ }^{1}$ and Brian Coyle ${ }^{2}$}

\begin{abstract}
This paper reports the findings of a small-scale study undertaken by one university - Glasgow Caledonian University- to test the state of "partnership working' between the university and placement providers. The study was conducted in two stages with 35 practice teachers responding to an on-line survey in stage one, and 16 practice teachers and students participating in interviews at stage 2. Overall findings indicate that the university has managed to sustain effective partnership working, despite organisational changes and resource constraints but that a number of improvements should be made to existing arrangements so that partnership working and the quality of practice learning can be further enhanced. It is evident that 'independent practice teachers' and 'work-based supervisors' have an increasing presence on the practice learning landscape, requiring a careful examination of their roles and responsibilities.
\end{abstract}

Keywords: partnership working; practice learning; practice teachers; students; Scotland

1. Senior Lecturer in Social Work

2. Brian Coyle, Lecturer in Social Work

Address for Correspondence: Ian Brodie, Senior Lecturer in Social Work, Glasgow Caledonian University, Cowcaddens Road, Glasgow G4 OBA, 0141331 3163, i.j.brodie@gcu.ac.uk.

Acknowledgement: The authors acknowledge the assistance of Learning Network West in providing statistics on placement provision in the West of Scotland.

8 J. of Practice Teaching \& Learning 13(2-3), pp.8-21. ๑ w\&b 


\section{Introduction}

It has been argued previously that social work in Scotland needs to be understood as distinct in many important respects from social work elsewhere in the UK (Brodie et. al., 2008). This is true also of social work education where there are a number of distinctive features of the Scottish system not always acknowledged in accounts of UK social work education (see for example, Wilson, 2014; Webber, 2015). The undergraduate social work degree in Scotland is four years' duration compared with three years elsewhere in the UK. The 'Framework for Social Work Education in Scotland' is based upon a combination of National Occupational Standards (NOS) with the QAA for Higher Education's Social Work Benchmark Statement for Social Work (and not just the NOS as it sometimes erroneously stated). There is no requirement in Scotland for formal partnerships to be established between universities and employers unlike in Northern Ireland (Wilson, 2014) and Wales (Care Council for Wales, 2013), and has been recommended for England (Social Work Reform Board, 2010; CroisdaleAppleby, 2014). This is not to suggest that partnership working in social work education is unnecessary or unimportant because clearly it is required, particularly if placements of sufficient quantity and quality are to be provided in a difficult environment. It does though put the onus on universities to develop and sustain partnerships with placement providers that are built on 'adequate arrangements' (SSSC, 2003) rather than binding agreements. This paper reports on a survey of practice teachers and students on perspectives on partnership working with placement providers developed by one university located in the West of Scotland. At the time the survey was conducted, the university had introduced a number of changes affecting practice learning - such as a new approach to assessment- and also, similar to other universities at this time, was contemplating further changes such as a reduction in the number of placement visits undertaken by tutors.

9 J. of Practice Teaching \& Learning 13(2-3), pp.3-7. ๑ w\&b 


\section{Partnership working in practice learning: Overview}

Partnership working is an important and growing phenomenon across a number of countries and continents, especially in the contexts of health and social care (Glasby and Dickinson, 2009). In relation to social work education, it is evident that the most frequently reported 'partnerships' are those between universities and placement providers (Hek, 2012; Scholar et. al., 2014; Wilson, 2014). It is also evident that other forms of partnership working are emerging. For instance, the benefits of sustained and meaningful partnerships between universities and service users increasingly are being realised and reported (Robson and Johns, 2006; Baldwin and Sadd, 2006; Mackay et. al., 2009; Mackay and Millar, 2012). A further interesting development are partnerships designed to strengthen the practice relevance of social work education - for instance, to enable the development of practice centres (Whipple et al, 2006; Tsien and Tsieu, 2007) and to facilitate students' direct involvement in community development projects (Blake, 2009; Gerstenblatt and Gilbert, 2014).

Campbell et. al. (2012) provide an evaluation of partnership arrangements between Further and Higher Education for the delivery of a 'Preparation for Practice' module at the University of Ulster. They acknowledge 'that collaborative partnership arrangements are complex and symbiotic affairs, which require the trust, respect and cooperation of all stakeholders' (2012:675). Two factors in particular emerged from their evaluation as being conducive to effective collaboration: good communication between participants and an acknowledgement of conflicting expectations in terms of the responsibilities and resources of those involved in the partnership.

In a further paper from Northern Ireland, Wilson (2014) reports on a study exploring perspectives of academic staff on partnership working with employers. He notes the long history of collaborative working in Northern Ireland, and comments on the 'collaborative advantage' that ensues from the current 'formal degree partnership' particularly in terms of high quality practice learning. Nevertheless, staff also commented on the time-consuming and bureaucratic structures that have been developed to sustain the partnership, and the over-emphasis on procedurally driven practice to the detriment of critical reflection. Writing from an English social work education perspective, Mann (2010)

10 J. of Practice Teaching \& Learning 13(2-3), pp.8-21. @ w\&b 
calls for closer partnership working between HEIs and local authority employers particularly to raise the quality of practice placements and to improve the support provided to practice educators.

Henderson (2010) reports on a small-scale study of work-based supervisors working in tandem with off-site practice teachers, undertaken in the south of England. She notes the increased anxiety and confusion about roles experienced by her study participants since the introduction of the new degree in 2003, and identifies the work-based supervisor as the 'neglected partner' within the placement team. Henderson (2010: 497) comments that 'key factors identified for successful partnerships were similar to previous studies such as ensuring regular flow of communication and agreeing mechanisms for resolving difficulties.'

Scholar et. al. (2014) consider the impact on the development of professional social work identity of placements in 'non-traditional' settings. The placements were provided by a UK-wide charity offering a 12-week personal development programme for young people at risk of social exclusion. Their study is confined to placements provided in England, and the wider context is the reforms to social work education in that country, following the establishing of the Task Force, Reform Board and then the College of Social Work in 2012. Scholar et. al. (2014) note that the placements provided by this charity mainly were first placements supervised by 'off-site' practice teachers. Some students commented that their views on what constituted social work had broadened by being in a 'non-traditional placement' although others expressed concern that the lack of a statutory placement would disadvantage them in their careers. Scholar et. al. (2014:1011) comment that 'in some non-traditional placement settings, SSWs properly supported by off-site practice educators, may find opportunities to advocate for and model social work possibilities, and to represent the profession by bringing a distinctive perspective, noted as such by nonsocial work staff and service users.' What is not covered to any extent is the potential role of placement partnerships to develop the quality and the relevance of 'non-traditional' placements.

Hek (2012) provides an evaluation of a project at the University of Birmingham designed to provide new practice learning opportunities in 'non-traditional' settings (with police and probation services). The stimulus to this initiative was a short-fall in final year social

11 J. of Practice Teaching \& Learning 13(2-3), pp.3-7. ๑ w\&b 
work placements, and more positively, a desire to increase student experience of inter-professional work. It is evident that a significant level of commitment was required both by the university and by the agencies to establish, and especially to sustain, these 'non-traditional' placements. As Hek (2012) concludes rather resignedly, innovation can be problematic in times of organisational cut-backs and upheaval.

\section{Practice learning: The West of Scotland context}

In the West of Scotland, social work placements have been provided through the Learning Network West (LNW) since the introduction of the new Honours Degree (4 year degree) in Social Work in 2004. The LNW is partly funded by employers and by the five universities accessing placements in the West of Scotland. The LNW acts as a 'broker' between the universities' demand for placements and the supply of these by a range of providers in the statutory, voluntary and independent sectors. This arrangement is intended to encourage efficient use of scarce resources, remove competition between universities and provide a single point of contact for negotiation over placement provision. In addition to assuming this 'broker' role, the LNW also employs an increasing number of Independent Practice Teachers (IPTs) and has responsibility for delivering (but not accrediting) the Practice Learning Award (PLA). There are no formal service level agreements in place, as recommended by Croisdale-Appleby (2014, p.55) but an expectation that local authorities will provide placements commensurate with the number of qualified social workers they employ.

In the period when this survey was conducted, the LNW provided 407 placements for five universities over the academic session. As Croisdale- Appleby (2014, p.49) notes, there is a continued problem for universities in obtaining sufficient placements, and this has been the case in the West of Scotland. In the past five years, there has been a noticeable trend towards an increasing use of 'Independent Practice Teachers' (IPTs) with $42 \%$ of all practice teachers being IPTs when this survey was undertaken. Another evident trend in the same time frame is the contraction in local authority provision of placements (now 68\% from approximately $85 \%$ five years ago) with a corresponding increase

12 J. of Practice Teaching \& Learning 13(2-3), pp.8-21. ๑ w\&b 
in voluntary sector provision (now 32\% compared with, five years ago, approximately 15\%). The reduction in local authority provision of placements in England is similarly noted by Croisdale-Appleby (2014, p.57) and has led to concerns that student expectations of having one statutory and one voluntary sector placement within their social work programme will not be fulfilled. Students, it is known, can view placements other than local authority area teams as not 'real placements' (Hek, 2012; Scholar et. al., 2014).

\section{Practice teacher and student survey}

The survey was conducted in two stages, reflecting the 'mixed methods' approach noted earlier (Bryman, 2008, p.623). Ethical approval was obtained through Glasgow Caledonian's 'School of Health and Life Sciences' ethics committee.

The initial stage involved an on-line survey (using 'Survey Monkey') of 86 practice teachers who at the time had students from either the undergraduate or postgraduate social work programmes at this university. The survey comprised a mix of closed and open ended questions, and included one 'Likert-type' question. 35 (41\%) practice teachers responded to the initial survey. In terms of the profile of respondents, this was similar to what was noted about the West of Scotland context at the time of the survey. For example, $46 \%$ of respondents were IPTs (compared with the overall proportion noted above of $42 \%$ ) with $66 \%$ of placements in the statutory sector (compared to $68 \%$ overall). Therefore, the profile of the respondents in terms of role and sector was reasonably representative of the West of Scotland context at that time. It also should be noted that nearly half of respondents (49\%) were experienced practice teachers in that they had supervised 10 or more students, including the current student for whom they had responsibility. The 'experience profile' of all practice teachers supervising West of Scotland placements at the time the survey was undertaken is not known.

The second stage of the survey involved telephone interviews with 8 practice teachers, who were selected from those currently working with the university to provide a 'purposive sample'. This took account

13 J. of Practice Teaching \& Learning 13(2-3), pp.3-7. ๑ w\&b 
of sector (with 5 practice teachers supervising statutory placements and 3 supervising voluntary placements); service user setting (reflecting the range of settings in which students were placed at that time); role (with 3 IPTs and 5 agency-employed practice teachers); gender ( 6 female and 2 male - representative of the gender profile of PTs working with the university at that time); and experience (with 2 PTs inexperienced; 4 fairly experienced; and 2 experienced).

The second stage sought to obtain the student perspective, with individual interviews undertaken with 8 students. The intention again was to obtain a 'purposive' sample in terms of programme (with equal representation of undergraduate and post graduate students); stage (equally divided between first and final placements); sector (with similar 'sector' proportions to those of the PTs); service user setting (with range similar to that of PTs); and gender and age (reasonably representative of the student profile at that time).

Therefore, while probability sampling was neither possible nor appropriate in the circumstances, the resulting samples both for the first and subsequent stages of the survey are thought to be reasonably representative of the practice teachers and students engaged with the social work programmes at that time, and consequently their perspectives provide a helpful insight into the university's partnership working in practice learning.

\section{Main Findings}

\section{Stage 1: On-line survey}

In terms of overall satisfaction, $94 \%$ of responding practice teachers indicated that they were either highly satisfied (26\%) or satisfied (69\%) working with the university. $88 \%$ either highly agreed (47\%) or agreed (41\%) that they would work with the university in the future. Responses can be summarised under two main themes: positive aspects of partnership working and areas for improvement in partnership working.

Positive aspects of partnership working

The four aspects that were mentioned most often by respondents were:

14 J. of Practice Teaching \& Learning 13(2-3), pp.8-21. (C) w\&b 
having a good relationship and communication with the university tutor; being provided with accessible and 'user-friendly' documentation; being given a good level of administrative support from the university; experiencing the university as responsive to problems or issues.

The following quotes illustrate the above noted positive aspects:

One of the positive aspects is meeting with the tutor and student and maintaining that relationship through the placement. I think it is important for us all to take responsibility for the learning opportunities and placement (PT 8).

The value of the relationship between university and student -you get the feeling the student is not just 'a number'. Any issues on placement are dealt with very quickly. Communication between PT, student and university is good (PT 28).

Course and paperwork are straightforward.....Course documents are reasonably easy to access on line (PT 10).

Good email communication from admin staff (PT 12).

From my personal point of view I was pleased with the way the tutor responded when I had a problem with my student.... it could have become a bigger problem if we hadn't dealt with it quickly. I felt the tutor concurred with my assessment of the situation and backed my approach and I how I dealt with it. This really gave me confidence in the whole process (PT 23).

Areas for improvement in partnership working

The four aspects that were mentioned most often by respondents were: reduction in meetings between tutors and practice teachers; introduction of new assessment guidelines; confusion between different documents; and need for improved preparation of students for placement. It is noteworthy that the first three aspects reflected recent changes made by the programme team, whereas the fourth aspect is indicative of a longerterm concern. The following quotes provide some insight into suggested areas for improvement:

Having pre, mid and final placement meetings are important for all the participants in the learning contract (PT 7).

15 J. of Practice Teaching \& Learning 13(2-3), pp.3-7. @ w w - b 
I have heard that the University wants to reduce the meetings between practice teacher, student and tutor but I feel this is wrong (PT 8).

I have serious reservations about the new system of including practice teachers as one of the markers of the whole portfolio. I feel it is more appropriate for us to mark the placement only as in the past. It means there is less objective distance between the practice teacher and the portfolio and previously I felt freer to give input regarding written work (PT 1).

Students could be better prepared before attending placement in relation to what it is actually like in reality. My student had no idea what supervision was and given that it was a 65 day placement we wasted 4 weeks going through the basics when the time could have been better spent on her reflective practice (PT 23).

\section{Stage 2: Individual Interviews}

The individual interviews produced similar themes to those emerging in stage 1 of the survey, but with some added depth and detail. There was sufficient over-lap between the views of both practice teachers and students to enable some common themes to be identified, but also one or two issues that were particular to each of the groups. The theme that received most frequent mention was the need for regular and clear communication between the university and placement providers. This was seen to be facilitated by placement workshops, mentioned positively by the majority of participants. Four students offered the view that improved attendance at workshops by practice teachers and work-based supervisors was needed. Six practice teachers highlighted the initial meeting between tutor, practice teacher, student and where involved, work-based supervisor, as being the most important in establishing the foundation of the placement. 2 students and 2 practice teachers specifically commented that changes made by the university affecting practice learning could be better communicated to, and should involve more consultation with, partners.

A second emerging theme was the need for detailed, accessible and up-to-date placement documentation. This reinforces the view reported in stage 1 of the survey, and relates to the third theme, of the need for a sound understanding of respective roles and responsibilities. The

16 J. of Practice Teaching \& Learning 13(2-3), pp.8-21. @ w\&b 
interviews contained some additional detail on this issue not evident in the on-line survey. For example, the role of the work-based supervisor was considered to be important, especially by students, but not always valued. Students specifically suggested that work-based supervisors should receive more training to undertake this role.

The fourth theme was of the desirability of a shared approach to problem-solving, again echoing a point emerging in the on-line survey. Two students, though, indicated that problems occurring within the placement were not always acted upon by the university which links to another view, evident in the student interviews, that procedures do not always sufficiently recognise the relative powerlessness of students in practice learning.

The final theme receiving significant mention was the need for improved preparation of students for practice learning, noted by three practice teachers. A similar number of students suggested that the university could provide more insights for partners into the academic demands on students while engaged in practice learning.

\section{Limitations of the study}

There are a number of limitations to this study which need to be acknowledged. Firstly, it is confined to the experiences of one university which limits significantly the generalizability of its findings. Secondly, as Alston and Bowles, 2013, p.133) note, on-line surveys tend to be completed by those most motivated, suggesting possible bias in response. Thirdly, the interviews involved small samples, again limiting generalizability. Finally, an important perspective missing from the survey is that of 'work-based supervisors'. Due to time constraints and limitations in data-bases, it did not prove possible to include work-based supervisors in this study although it would be intended to include them in any further research.

17 J. of Practice Teaching \& Learning 13(2-3), pp.3-7. @ wE-b 


\section{Conclusion}

The evidence from this small-scale study indicates that the university is managing to sustain partnership working despite organisational changes and resource constraints. Three particular features of 'partnership working' can be highlighted which, to some extent, reflect the perspectives and experiences reported in the reviewed literature.

Firstly, the need for regular and effective communication which echoes the experience of others (Henderson, 2012; Campbell et. al., 2012).This is manifested in tangible ways such as accessible and accurate documentation which includes clarification of roles and responsibilities; opportunities for meeting together such as workshops; and on-going and open contact between tutors and practice teachers. There can be a negative impact on the partnership when this communication lapses, such as inadequate communication about change.

Secondly, the need for a commitment to shared problem-solving. This supports the view expressed by Henderson (2010) of having mechanisms in place to resolve difficulties. The practice teachers in this survey who experienced a shared approach to resolving problems did value this approach. On the other hand, it is clear that some students did not feel that current arrangements worked well, and felt relatively powerless when problems occurred.

Thirdly, the need for better preparation for students for practice learning. This is a strong argument emerging from the evaluative work undertaken in Northern Ireland since the implementation of the 'new' degree in 2003 (Wilson, 2013; Wilson, 2014). With the increasing diversity of placements, and the 'opening up' of non-traditional placements (Hek, 2012; Scholar et. al., 2014) arguably such preparation will become even more necessary, especially to 'bridge the gap' perceived to exist between academia and practice (Mann, 2010).

There are two other factors emerging from this survey which merit consideration. Firstly, is the increasing significance of 'independent practice teachers' in practice learning, with nearly half of the practice teachers supervising placements in the West of Scotland when this survey was undertaken having this status. There are legitimate concerns to be raised about the accountability and the monitoring of 'independent practice teachers'. This is especially the case if universities concede to

18 J. of Practice Teaching \& Learning 13(2-3), pp.8-21. () w\&b 
pressures to cut-back on tutor visits to placements. Secondly, our survey reinforces the view of Henderson (2010) that work-based supervisors are the 'neglected partners' in practice learning through our omission of them from our sample and through the view of some students that their contribution to placements was important but not necessarily valued.

In response to this survey, the university has maintained its commitment to tutors having at least two contacts per placement, has reviewed the clarity of its documentation, and has implemented on both the undergraduate and postgraduate programmes a practice learning curriculum that includes significant contributions from placement providers.

Partnership working does require commitment especially at a time of organisational change and significant resource constraints but it is essential to the enhancement of the quality of practice learning.

\section{References}

Alston, M. and Bowles, W. (2013) Research for Social Workers. An introduction to methods. Abingdon: Routledge

Baldwin, M. and Sadd, J. (2006) Allies with attitude! Service users, academics and social service agency staff learning how to share power in running social work education courses. Social Work Education, 25, 4, 348-359

Blake, J. (2009) Sustainable communities and social work practice: reflections on emergent, learning partnerships, Journal of Practice Teaching and Learning, 9, 2, 93-114

Brodie, I., Nottingham, C. and Plunkett, S. (2006) A Tale of Two Reports: Social Work in Scotland from Social Work and the Community (1966) to Changing Lives (2006). British Journal of Social Work, (2008) 38, 697-715

Bryman, A., (2008) Social Research Methods. (3 ${ }^{\text {rd }}$ ed.) Oxford: Oxford University Press

Campbell, A, McCall, S., Eagleson, H. and McGinnis, E. (2012) An evaluation of the effectiveness of an FE/HE Partnership in the delivery of a preparation for practice module within an undergraduate social work degree programme. Social Work Education, 31:5, 663-677

Care Council for Wales (2013) The Framework for the Degree in Social Work in Wales, 2012. Cardiff: Care Council for Wales

19 J. of Practice Teaching \& Learning 13(2-3), pp.3-7. @ wE-b 
Croisdale-Appleby, D (2014) Re-visioning Social Work Education. An Independent Review.London: DoH

Gerstenblatt, P. and Gilbert, D.J. (2014) Framing service learning in social work: an interdisciplinary elective course embedded within a universitycommunity partnership. Social Work Education, 33:8, 1037-1053

Glasby, J. and Dickinson, H. (2009) International Perspectives on Health and Social Care: Partnership working in action. Chichester: Blackwell

Hek, R. (2012) Is it possible to develop and sustain non-traditional placements? an evaluation of the development of practice learning opportunities in partnership with the Police and Probation Services in the West Midlands. Social Work Education, 31, 4, 512-529

Henderson, K.H. (2010) Work-based supervisors: The neglected partners in practice learning. Social Work Education, 29:5, 490-502

MacKay, R., Fairclough, M. and Coull, M. (2009) Service users and carers as co-educators of social work students. The Journal of Practice Teaching $\&$ Learning, 9, 1, 95-112

MacKay, R. and Millar, J (2012) Involving service users in the classroom with social work students. Nurse education today, 32, 2, 167-172

Mann, T. (2010) Personal reflections of social work education in the context of the Social Work Task Force, Practice: Social Work in Action, 22, 5, 321-329

Robson, P. \& Robert, J. (2006) Strengthening partnership, Social Work Education, 25:4, 320-325

Scholar, H., McLaughlin, H., McCaughan, S. and Coleman, A. (2014) Learning to be a social worker in a non-traditional placement: Critical reflections on social work, professional identity and social work education in England, Social Work Education, 33:8, 998-1016

Scottish Social Services Council (2003) Rules for Social Work Training. Dundee: SSSC

Social Work Reform Board (2010) Building a Safe and Confident Future: One year on. Detailed proposals from the Social Work Reform Board, Department for Education, London

Tsien, T.K.B. \& Tsui , M-S. (2007) A Participative learning and teaching model: The partnership of students and teachers in practice teaching, Social Work Education, 26:4, 348-358

Webber, M (2015) (ed.) Applying Research Evidence in Social Work Practice. London: Palgrave

Whipple, E.E., Solomon-Jozwiak, S., Williams-Hecksel, C., Abrams, L.A. and Bates, L. (2006) Preparing social workers for child welfare practice: An

20 J. of Practice Teaching \& Learning 13(2-3), pp.8-21. ๑ w\&-b 
innovative university-agency learning collaborative. Social Work Education, 25, 1, 92-107

Wilson, G. (2014) Building partnerships in social work education: Towards achieving collaborative advantage for employers and universities. Journal of Social Work, 14, 1, 3-22

Wilson, G (2013) Preparing social workers for practice: Re-evaluating student learning needs. Social Work Education, 32:5, 590-606

Wilson, G. (2012) Reforming social work education: Some reflections on the contribution of practice learning. Practice (UK), 24, 4, 225-237

21 J. of Practice Teaching \& Learning 13(2-3), pp.3-7. ๑ w\&b 